\title{
Life Cycle Assessment Contribution in the Product Development Process: Case Study of Wood Aluminum-Laminated Panel
}

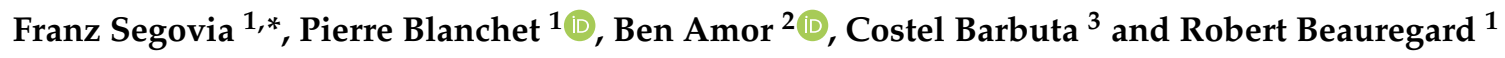 \\ 1 Department of wood and forest sciences, Laval University, Quebec City, QC G1V 0A6, Canada; \\ pierre.blanchet@sbf.ulaval.ca (P.B.); robert.beauregard@sbf.ulaval.ca (R.B.) \\ 2 Department of Civil and Building Engineering, Interdisciplinary Research Laboratory on Sustainable \\ Engineering and Ecodesign (LIRIDE), University of Sherbrooke, Sherbrooke, QC J1K 2R1, Canada; \\ ben.amor@usherbrooke.ca \\ 3 Department of Secondary Manufacturing, FPInnovations, Montreal, QC G1V 4C7, Canada; \\ costel.barbuta@fpinnovations.ca \\ * Correspondence: franz.segovia-abanto.1@ulaval.ca
}

Received: 7 February 2019; Accepted: 5 April 2019; Published: 15 April 2019

\begin{abstract}
The benefits of aluminum lamination in improving the physical and mechanical properties of wood-based composites is now well documented. This paper shows the contribution of life cycle assessment (LCA) as a tool to assess and compare the environmental footprint in the development of laminated panels. SimaPro 9.0 software, using Ecoinvent database was used to analyze the environmental impacts associated with the manufacturing of wood aluminum-laminated (WAL) panels and aluminum honeycomb panel (AHP). The impact 2002+ method was used to estimate environmental impacts. The LCA results show that the WAL panels manufacturing had a lower environmental impact than AHP manufacturing. In term of product, wood-based composites were the best choice as a core in laminated panel manufacturing. Wood-based composite manufacturing showed environmental advantages in all damage categories except in ecosystem quality. Aluminum alloy sheets manufacturing played an important role in the generation of environmental impacts for laminated panel development.
\end{abstract}

Keywords: product development; wood-based composite; aluminum alloy sheet; laminated panel; LCA; environmental performance

\section{Introduction}

Life cycle assessment (LCA) is widely accepted in manufacturing industries as the most important way to integrate environmental concerns into product development [1]. LCA approach has great importance in the different stages of the product development process: concept design, part design, process design and decision-making [2]. During each stage of the product development process, aspects such as technical, ergonomic, economic, health and environmental properties are taken into account for the development of the final product [1]. The applications of LCA come in different forms such as impact assessment, selection, classification and decision support [2]. The main benefit of using LCA in composites development is that it provides a comprehensive way of determining the total environmental impact for designing new materials and processes [3]. The LCA methodology is an important tool to assist in ensuring proper sustainability through assessing the environmental burdens associated with the development of a product [4]. This methodology is a useful tool for choosing clean production processes, avoiding hazardous and toxic materials, maximizing the efficiency of the energy used for production and for the product in use, and designing for waste management and recycling [3]. 
The province of Quebec (Canada) is a world-leading producer of aluminum and wood-based composites. The wood aluminum-laminated (WAL) panels that involve the use of those materials has the potential to bring new opportunities for innovation to the local industry. A competitive advantage would be the good environmental performance of WAL panel in comparison to other materials. Wood-based composites panels present variable physical and mechanical properties, as a result of their structure and process engineering as well as, these engineering process also can improve the environmental performance and sustainability of wood-based composites [5].

Among the main types of wood-based composites panels produced are the high-density fiberboard (HDF), medium-density fiberboard (MDF), oriented strand board (OSB), particleboard (PB) and plywood. Wood-based composites panels offer good properties but also certain weaknesses such as their limited mechanical properties, poor water resistance, dimensional instability and limited durability. These properties limit their use in applications involving exposure to wet environment conditions. Many high-performance laminated panels (sandwich structures) are available, these are widely used in aircraft, automotive, marine, and other structural applications where strength, stiffness and weight efficiency are required and where the environmental conditions (temperature, flammability and moisture/humidity) play an important role in the selection of materials. Different material combinations from cores and face sheets have been developed. Some are polymer, fiber or metal based. Among the properties of these laminated panels, high mechanical properties, high strength/weight ratio and dimensional stability are differentiating properties. Most of these panels are presenting some better properties than usual wood-based composite but at a much higher price per square meter. In order to allow wood-based composite to reach some application associated to these high-performance panels a wood aluminum-laminated panel has been developed [6], which have involved, apart from the study of their physical and mechanical properties, the study of their environmental performance assessment.

The relationship between the building industry and environmental pollution is widely discussed. A recent study suggested that buildings globally are responsible for half of the world greenhouse gas emissions [7]. Several studies have been carried out to analyze environmental performance assessment of various wood-based composites. HDF and MDF panels have been studied extensively [5,8-11]. The studies identified hotspots in MDF manufacturing as the gas consumption, urea-formaldehyde resin, power consumption, wood chip consumption and wood chip transportation [12,13]. Similarly, OSB panel, which is an engineered structural-use panel, has also been studied $[6,14,15]$. The hotspots identified in OSB manufacturing were production of the petroleum-based chemicals as methylene diphenyl diisocyanate (MDI) resin and the diverse emissions derived from activities in the OSB manufacturing as the burning of biomass waste [9]. Finally, softwood plywood panels have also been studied $[16,17]$.

One of the environmental advantages of wood-based composites manufacturing is the utilization as energy of the combustion of wood fuel (biomass), which is normally composed of wood residues (wood and bark), generated during their manufacture. For instance, the most outstanding fact of OSB manufacturing is that $82 \%$ of heat energy required is generated on-site from combustion of wood fuel (biomass). This energy generated by renewable fuels represents about $38 \%$ of the total energy from cradle-to-gate of OSB panel [6]. Likewise, the energy generated by renewable fuels, such as woody biomass, represents about $59 \%$ or $56 \%$ of the total energy from cradle-to-gate from softwood plywood [16,17]. In this softwood plywood case, of total $\mathrm{CO}_{2}$ emissions, $69 \%$ were $\mathrm{CO}_{2}$ biogenic-based emissions from the combustion of wood fuel [16]. The use of wood for fuel as an energy source plays a significant and favorable environmental role. Emissions of $\mathrm{CO}_{2}$ biogenic due to the combustion of wood, are often referred to as having a neutral impact on global warming [18]. Among other sources, this is acknowledged by the United States Environmental Protection Agency, whereas $\mathrm{CO}_{2}$ due to the combustion of fossil fuels contributes significantly to global warming [10]. Although there is still some level of controversy about this issue, the conditions allowing the realization of carbon emission benefits are increasingly well known [19]. However, the use of petroleum-based adhesives (amino resins) in the manufacturing of wood-based composites is considered the main source of environmental impact [20]. 
Amino resins are formaldehyde-based materials providing strength and resistance. Urea-formaldehyde (UF) resins are used for interior products, melamine urea-formaldehyde (MUF) resins and phenol formaldehyde (PF) resins are used for exterior products. Within the petroleum-based adhesives, the MUF shows a higher carbon footprint in comparison with other types of adhesives such as PF, phenol resorcinol formaldehyde or UF [21]. Formaldehyde air emission decreases as the melamine content increases in the MUF, which is one of the key environmental problems of formaldehyde-based resins [22].

Several studies have been conducted to determine the environmental impact of other natural fiber-based composite panels using the life cycle analysis methodology [23-27]. According to these studies, the composite panels made with natural-based polymers shows favorable results in terms of environmental impact and energy consumption in comparison with petroleum-based panels, but in both composite panels, the use of epoxy resin was the major contribution to the environmental impact, up to more than $85 \%$ [24]. However, the use of wood fibers as reinforcement in composite panel shows environmental advantage compared with the polypropylene [27]. The use of balsa wood as core in laminated panels shows also environmental advantages compared to polyvinyl chloride or steel [26].

As mentioned previously, the laminated materials used as face sheet or skin are numerous, including glass, carbon fiber or metals. Among the metals, of particular interest is aluminum. Aluminum is the second-most used metal after steel, and in the last few decades its use has increased due to his versatile properties [28]. The environmental impact caused by the production of aluminum has been studied extensively to improve the smelting technologies, energy consumption, solid waste management and raw material consumption worldwide [28-33]. LCA studies on aluminum production showed different results possibly because of the limited geographical life cycle scope and differentiated system boundaries, popularity to use industry-wide inventory data, and predominant focus on greenhouse gas emissions [33]. Generally, the aluminum production requires much more energy than other metals and causes large amounts of greenhouse gas emissions [30], when fossil fuel, black coal, or natural gas are used, which is not the case when hydroelectricity is used, such as in the jurisdiction of Quebec. Energy conservation and emissions reduction have long been a key concern for the sustainability of aluminum industry [28]. Consequently, the aluminum alloy made from secondary, recycled aluminum presents environmental and economic benefits compared to primary aluminum, due to much reduced electricity consumption and global warming gas score respectively $[29,34]$. Furthermore, aluminum can be recycled almost indefinitely.

The current paper aims to determine the importance of the LCA approach in the development process of WAL panels. The present attributional LCA study compare WAL panel manufacturing with different types of cores (MDF, OSB and plywood) and the aluminum honeycomb panel (AHP) manufacturing since their physical and mechanical properties were established as similar [35] according to a cradle-to-gate approach. The assessment of the environmental impacts of laminated panels through a LCA methodology will allow to identify the environmental hotspot of each panel throughout the manufacturing process and to explore the opportunities for environmental improvements of WAL panels. The results of the comparative LCA study will allow decision-making considering highlight environmental impact of WAL panels compared to AHP within of the framework of the product development process. Future work should demonstrate the advantages of using WAL panels in different potential applications.

\section{Methodology: Life Cycle Assessment (LCA)}

Environmental performance analysis of WAL panel and AHP have been carried out according to the LCA following ISO 14040 and ISO 14044 standards [36,37]. LCA typically includes the following four phases: goal and scope definition, inventory analysis, life cycle impact assessment and interpretation phase [36]. This LCA study has been modeled using SimaPro 9.0 software with database support from Ecoinvent v3.5 [38]. 


\subsection{Goal and Scope of the Study}

\subsubsection{Functional Unit (FU)}

In LCA, the FU is defined to quantify the function of a product system. This provides the reference for inputs and outputs [36]. In this paper, the functional unit was defined as the manufacture of laminated panel of one square meter per $10 \mathrm{~mm}$ of thickness able to withstand a load of $6.0 \mathrm{kgf} / \mathrm{mm}^{2}$, as an interior floor.

\subsubsection{Definition of System Boundary from Cradle-to-Gate}

The purpose of this study is to assess the contribution of LCA in the product development process and taking into account that predicting the end-of-life of such product is highly uncertain, the analysis is delimited by cradle-to-gate system boundaries. Consequently, raw material extraction, manufacturing of components (wood-based composite, aluminum alloy sheets and adhesive), and manufacturing of laminated panels are included in the modeling. The system boundaries for both products are shown in Figure 1.

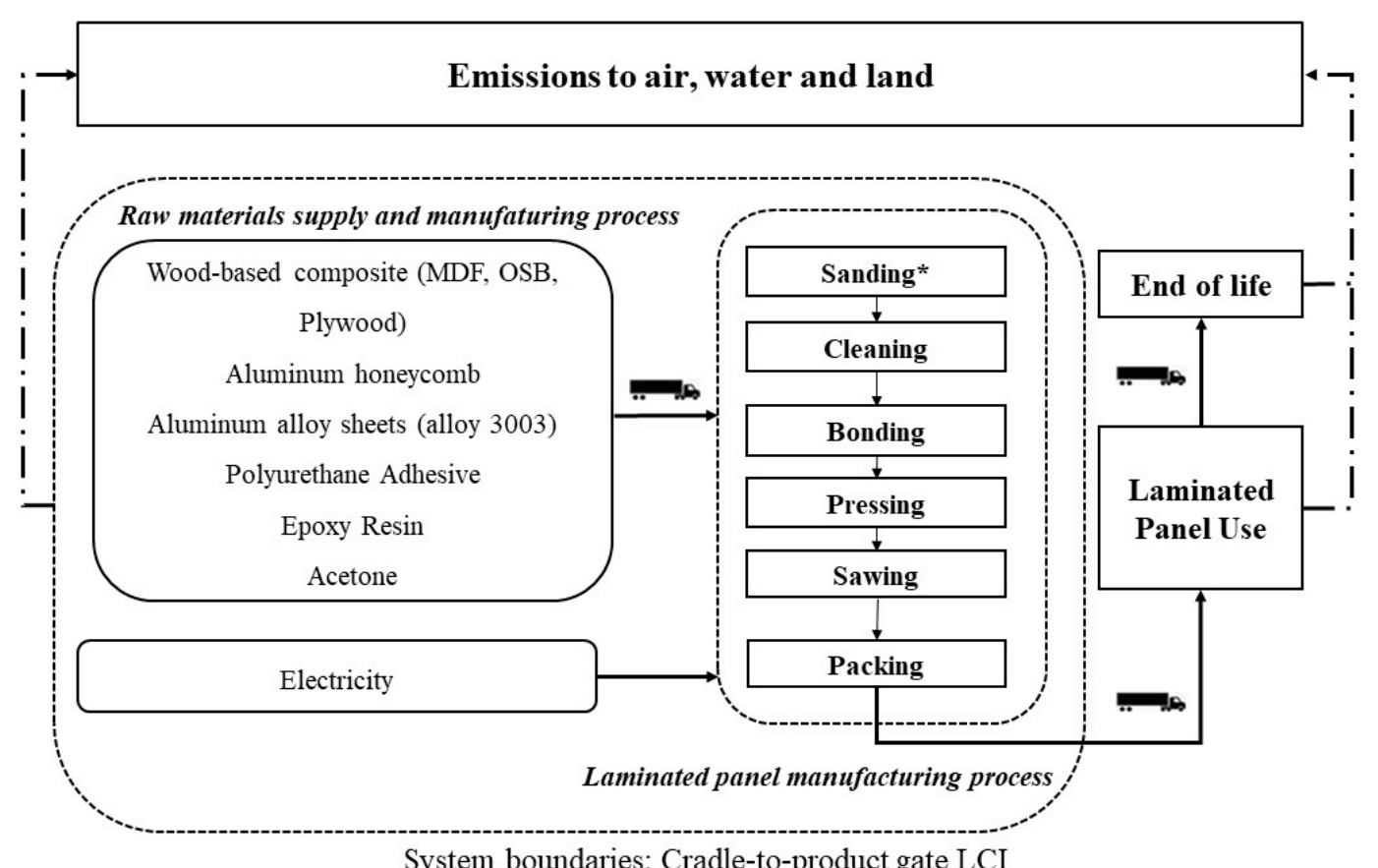

Figure 1. Cradle-to-gate Life cycle boundaries of wood aluminum-laminated panels and aluminum honeycomb panel. *Wood Aluminum-Laminated (WAL) panels manufacturing. MDF: Medium-Density Fiberboard; OSB: Oriented Strand Board; LCI: Life Cycle Inventory.

\subsubsection{Description of the Studied Panels}

Three WAL panels with three different cores, MDF, OSB and plywood, were produced. The wood panels are laminated with two aluminum alloy sheets to form a sandwich structure (Figure 2). For comparison, an aluminum honeycomb panel (AHP) was also studied. These four laminated panels presented similar physical and mechanical properties [35]. 
(a)
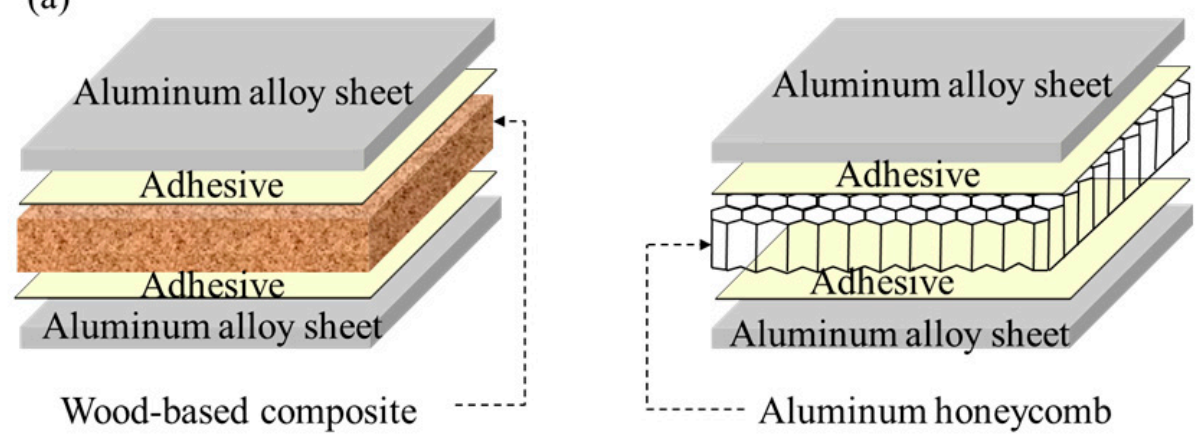

(b)

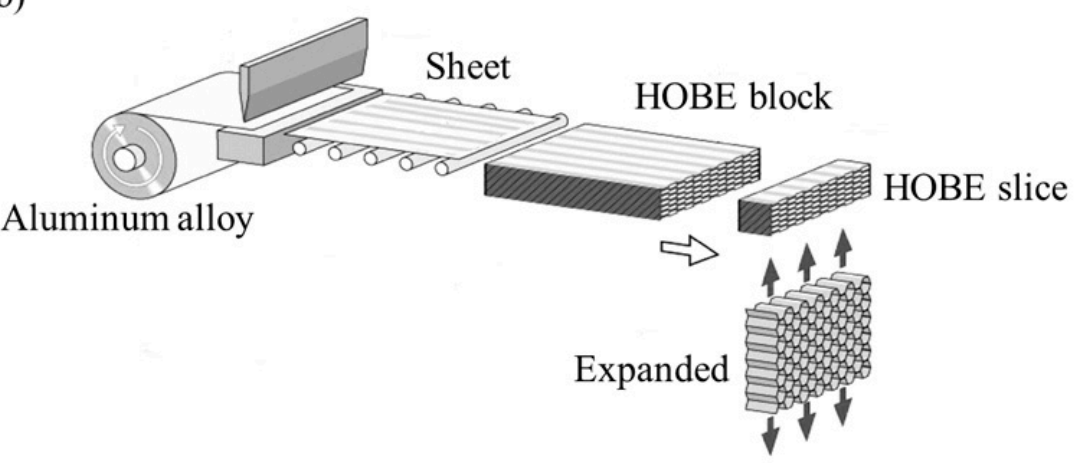

Figure 2. (a): Typical layout of wood aluminum-laminated panel and Aluminum honeycomb panel.

(b): Aluminum honeycomb manufacturing process. HOBE: HOneycomb Before Expansion

The main physical and mechanical properties of the WAL and aluminum honeycomb panels are presented in Table 1. The properties were determined according to American Society for Testing and Materials (ASTM) Standard D1037.06a [39].

Table 1. Physical and mechanical properties of the WAL panels and AHP [35].

\begin{tabular}{ccccc}
\hline Main Features & \multicolumn{2}{c}{ Wood Aluminum-Laminated Panels } & Aluminum Honeycomb Panel \\
\hline Core material & MDF & OSB & Plywood & Aluminum Honeycomb \\
\hline Thickness (mm) & 10.89 & 11.47 & 10.15 & 10.00 \\
Face sheet thickness (mm) & 0.6 & 0.6 & 0.6 & 0.6 \\
\hline Physical Properties & & & & 4.60 \\
Areal Weight $\left(\mathrm{kg} / \mathrm{m}^{2}\right)$ & 10.50 & 11.47 & 10.15 & - \\
\hline Thickness swelling (\%) (24-h water soaking) & 16.17 & 2.46 & 1.65 & - \\
Water absorption (\%) (24-h water soaking) & 19.70 & 11.37 & 12.73 & 19,570 \\
\hline Mechanical Properties & \multicolumn{5}{c}{102} \\
\hline Module of elasticity (MPa) & 18,267 & 17,354 & 19,323 & 125 \\
Module of rupture (MPa) & 90 & 61 &
\end{tabular}

\subsubsection{Description of Manufacturing Process of the Wood Aluminum-Laminated Panel}

Wood-based composite manufacturing: WAL panel were manufactured with three types of wood-based composite panels used as cores (MDF, OSB and plywood). The wood-based composites panels were obtained on the market as produced by the manufacturers. Wood-based composites are usually manufactured by mixing wood particles, flakes or fibers together with resin. This mixture is formed into a sheet, which is compressed with heat to cure the resin and to determine the final thickness of the panel. 
The processes for producing wood-based composite materials can be found in prior studies [40]. MDF is frequently used in place of solid wood, plywood, and particleboard in many furniture applications. It is also used for interior door skins, moldings, and interior trim components. MDF manufacturing includes the residues (shavings, sawdust, ply trim, and chips), transportation delivery of residues, operations as screening, digesting, disk refining, blending, drying, forming, pre-pressing, mat trimming, hot pressing, panel conditioning, sawing, sanding, packaging, and materials such as resin and wax. OSB is usually made up of three layers of strands aligned in the long-direction of the panel and a core layer that is counter-aligned or laid randomly using the smaller strands or fines [40]. OSB manufacturing panel include forestry operations, round wood transportation, operations as log handling, flaking, drying, screening, blending, mat formation, hot pressing, finishing, packaging, and materials as resin and wax. The plywood is a panel built up wholly or primarily of sheets of veneer called plies. It is constructed with an odd number of layers with the grain direction of adjacent layers oriented perpendicular to one another [40]. The plywood manufacturing include also forestry operations, roundwood transportation, operations as bucking, debarking, block conditioning, peeling, clipping, drying, hot pressing, trimming, sawing, packaging, and materials as resin. The wood-based composite manufacturing process also requires heat and electrical power.

Aluminum alloy sheet manufacturing: Aluminum alloy sheets 3003 were used as face sheet. Aluminum alloy sheet manufacturing process includes mining bauxite, primary aluminum production, aluminum alloy production, aluminum sheet production, and transport. The aluminum is produced from bauxite (primary). Virtually all the world's primary aluminum is produced via the well-established Bayer process for alumina from open-pit mined bauxite, followed by Hall-Héroult electrolysis [28]. The aluminum smelters produce primary aluminum with $99.7-99.9 \%$ purity. The main impurities are iron and silica. Alloy elements are added to improve the mechanical strength of pure aluminum, the aluminum alloy production process include the use of chemical components. Approximately 15 elements are used in various combination, but six or seven are more important (copper, manganese, silicon, magnesium, zinc). The pure aluminum is maintained at temperatures between $650{ }^{\circ} \mathrm{C}$ to $800^{\circ} \mathrm{C}$. Alloy elements are previously mixed according to the recipe and then added to pure aluminum. The aluminum alloy is purified by injecting a gas and finally it is placed into molds. The aluminum alloy sheet production includes the process of ingot aluminum cleaning to remove the oxide layer. The ingot is then heated between $350{ }^{\circ} \mathrm{C}$ to $550{ }^{\circ} \mathrm{C}$ and press rolled to produce a sheet of the final thickness. When thinner sheets are required, the aluminum alloy sheet must be compressed in cold rolls to less than $60^{\circ} \mathrm{C}$ [41].

Wood Aluminum-Laminated panel manufacturing: The aluminum alloy sheets were sanded with a 150-grit sandpaper and cleaned with acetone for degreasing. Wood-based composites were sanded with a 120-grit sandpaper. A liquid polyurethane adhesive (Macroplast UR-8346) provide by Henkel Corporation was applied at a spread rate of $130 \mathrm{~g} / \mathrm{m}^{2}$. Two aluminum alloy faces and one wood-based composite were assembled in a Diefenbaker laboratory hot press at $689 \mathrm{kPa}$ and $120{ }^{\circ} \mathrm{C}$ for six minutes to ensure full curing of the adhesive. The production flow of the WAL panel manufacturing can be seen in Figure 1. The manufacturing process was modeled (Figure 1) based on actual laboratory procedures. The modeling includes the packaging of WAL panels.

\subsubsection{Description of Manufacturing of the Aluminum Honeycomb Panel}

Aluminum honeycomb manufacturing: The aluminum honeycomb process, using adhesive bonding, is illustrated in Figure $2 b$. The expansion process is a technique used to make honeycomb. It consists in the printing of adhesives lines on the aluminum sheets cleaned prior to application. These sheets are cut and stacked, after the adhesive lines are cured under pressure at high temperature. The honeycomb before expansion block (HOBE block) is cut into slices according to required thickness. Finally, the aluminum HOBE slices are expanded [42]. 
Aluminum Honeycomb panel manufacturing: The material flow of the AHP manufacturing is illustrated in Figure 1. The aluminum alloy sheets previously cleaned and the aluminum honeycomb are bonded, an adhesive film is placed on top and the bottom surfaces of the honeycomb, upon which aluminum alloys sheets are placed. This whole assembly is cured also under pressure and high temperature. During the pressing process, the resin flows and creates a bond between the aluminum alloy sheets and the aluminum honeycomb walls.

\subsubsection{Assumption and Limitation}

Various assumptions have been made throughout the life cycle assessment of both panel types (WAL panels and AHP).

- The packing stage has been excluded of assessment of environmental impacts because they are considered identical for the four types of laminated panels.

- All data for the WAL panel manufacturing process was obtained from laboratory tests and adapted in the modeling to reflect the industrial context.

\subsection{Life Cycle Inventory}

Life cycle inventory analysis is carried out in order to quantify the inputs and outputs associated with the life cycle stages of both types of laminated panels. As indicated in Figure 1, the system modeling was divided into two stages for laminated panels manufacturing: the raw materials supply and the laminated panels manufacturing process. The following paragraphs show in detail which data is used for the modeling of the system.

Wood-based composites data: For wood-based composites, the datasets were calculated according to the functional unit ( $1 \mathrm{~m}^{2}$ of panel). For MDF panel, the dataset was adapted according to the context of the province of Quebec. The electricity parameter was considered as from Quebec. Instead, for OSB and plywood panels, the dataset was used directly from Ecoinvent, as the latter already contain Quebec specific datasets.

Aluminum alloy sheet data: As in the previous case, the input and output information was obtained from the Ecoinvent database. The datasets were calculated according to functional unit. The chemical composition of aluminum alloy in dataset was adapted to aluminum alloy 3003. Furthermore, the electricity parameter was considered as from Quebec. This data also includes the transportation phase.

WAL panels and AHP manufacturing data: The input information for panels was determined based on laboratory work and datasheets. The dataset was calculated according to the functional unit (Table 2). The adhesive consummation of WAL panels was calculated in laboratory in a previous study [35], while that for aluminum honeycomb panels was obtained of datasheets. The sanding and pressing parameters and their respective electricity consumption of each machine were calculated in laboratory according to their machine datasheet for each WAL panel. The electricity consumption of each machine for aluminum honeycomb panel was calculated according to machine datasheet and the province of Quebec energy grid mix. 
Table 2. WAL panels and Aluminum Honeycomb Panel (AHP) manufacturing inventory data (1 $\mathrm{m}^{2}$ of laminated panel).

\begin{tabular}{|c|c|c|c|}
\hline Laminated Panels Manufacturing & Based on Process & Quantity & Source of Data \\
\hline \multicolumn{4}{|c|}{ Wood Aluminum-Laminated Panels } \\
\hline \multicolumn{4}{|c|}{ Raw Materials Supply } \\
\hline MDF & Medium-density fibreboard $\{\operatorname{RoW}\} \mid$ medium-density fibre board production, uncoated | Alloc Rec, $U$ & $1 \mathrm{~m}^{2}$ & Ecoinvent 3.5 * \\
\hline OSB & Oriented strand board $\{C A-Q C\} \mid$ production $\mid$ Alloc Rec, $U$ & $1 \mathrm{~m}^{2}$ & Ecoinvent 3.5 \\
\hline Plywood & Plywood, for outdoor use $\{C A-Q C\} \mid$ production | Alloc Rec, $U$ & $1 \mathrm{~m}^{2}$ & Ecoinvent 3.5 \\
\hline Aluminum allov sheets & Aluminum alloy, $\mathrm{AlMg}_{3}\{\mathrm{CA}-\overline{\mathrm{QC}}\} \mid$ production | Alloc Rec, $\mathrm{U}$ & $3280 \mathrm{~kg}$ & Ecoinvent 3.5 * \\
\hline & Sheet rolling, aluminum $\{C A-Q C\} \mid$ processing $\mid$ Alloc Rec, $U$ & & Ecoinvent 3.5 \\
\hline Polyurethane & Polyurethane, flexible foam $\{$ RoW $\} \mid$ production | Alloc Rec, $\mathrm{U}$ & $0.130 \mathrm{~kg}$ & Ecoinvent $3.5^{*}$ \\
\hline \multicolumn{4}{|l|}{ Processes } \\
\hline Degreasing & Degreasing, metal part in alkaline bath $\{$ RoW $\} \mid$ processing $\mid$ Alloc Rec, $U$ & $2 \mathrm{~m}^{2}$ & Ecoinvent 3.5 \\
\hline Electricity (All processes) & Electricity, medium voltage $\{C A-Q C\} \mid$ market for | Alloc Rec, $U$ & $6.95 \mathrm{kwh}$ & Ecoinvent 3.5 \\
\hline \multicolumn{4}{|c|}{ Aluminum Honeycomb Panel } \\
\hline \multicolumn{4}{|c|}{ Raw Materials Supply } \\
\hline Aluminum Honeycomb & & $1 \mathrm{~m}^{2}$ & Built \\
\hline Aluminum alloy sheets & Aluminum alloy, $\mathrm{AlMg}_{3}\{\mathrm{CA}-\mathrm{QC}\} \mid$ production | Alloc Rec, $\mathrm{U}$ & $1.549 \mathrm{~kg}$ & Ecoinvent $3.5 *$ \\
\hline 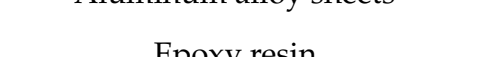 & Sheet rolling, aluminum $\{C A-Q C\} \mid$ processing $\mid$ Alloc Rec, $U$ & $0132 \mathrm{~kg}$ & Ecoinvent 3.5 \\
\hline & $\begin{array}{l}\text { Adhesive, for metal }\{\mathrm{RoW}\} \mid \text { production } \mid \text { Alloc } \mathrm{Rec}, \mathrm{U} \\
\text { Aluminum alloy, } \mathrm{AlMg}_{3}\{\mathrm{CA}-\mathrm{QC}\} \mid \text { production } \mid \text { Alloc } \mathrm{Rec}, \mathrm{U}\end{array}$ & & $\begin{array}{l}\text { Ecoinvent } 3.5 \\
\text { Ecoinvent } 3.5 \text { * }\end{array}$ \\
\hline Aluminum alloy sheets & Sheet rolling, aluminum $\{C A-Q C\} \mid$ processing $\mid$ Alloc Rec, $U$ & $3.280 \mathrm{~kg}$ & Ecoinvent 3.5 \\
\hline Epoxy resin & Adhesive, for metal $\{$ RoW $\} \mid$ production | Alloc Rec, $\mathrm{U}$ & $0.200 \mathrm{~kg}$ & Ecoinvent 3.5 \\
\hline \multicolumn{4}{|l|}{ Processes } \\
\hline Degreasing & Degreasing, metal part in alkaline bath $\{$ RoW $\} \mid$ processing $\mid$ Alloc Rec, $U$ & $2 \mathrm{~m}^{2}$ & Ecoinvent 3.5 \\
\hline Electricity (All processes) & Electricity, medium voltage $\{C A-Q C\} \mid$ market for | Alloc Rec, $U$ & $65.23 \mathrm{kwh}$ & Ecoinvent 3.5 \\
\hline
\end{tabular}

${ }^{*}$ Adapted to the assessed product. 


\subsection{Life Cycle Impact Assessment Method (LCIA)}

The results of the LCIA were calculated using the IMPACT2002+ version 2.15 method [43]. This method is one of the most widely used method in LCA analysis. The IMPACT2002+ method suggests a feasible implementation of a combined midpoint/damage approach, linking all types of life cycle inventory results (elementary flows and other interventions) via several midpoint categories to several damage categories. This method defines 15 mid-point categories including carcinogens, non-carcinogens, respiratory inorganics, ionizing radiation, ozone layer depletion, respiratory organics, aquatic ecotoxicity, terrestrial ecotoxicity, terrestrial acidification, land occupation, aquatic acidification, aquatic eutrophication, global warming, non-renewable energy and mineral extraction.

These mid-point categories are grouped into four damage categories: human health (carcinogens, non-carcinogens, respiratory inorganics, ionizing radiation, ozone layer depletion, and respiratory organics midpoints) expressed in DALY (disability-adjusted life year); ecosystem quality (aquatic ecotoxicity, terrestrial ecotoxicity, terrestrial acidification, and land occupation mid-points) expressed in $\mathrm{PDF}^{*} \mathrm{~m}^{2 *} \mathrm{yr}$; climate change (global warming midpoint) expressed in $\mathrm{kg} \mathrm{CO}_{2}$-eq and the resources depletion (non-renewable energy and mineral extraction midpoints) expressed in megajoule (MJ) primary.

Sensitivity analysis: The purpose of sensitivity analysis is to show if a change of a certain input parameter affects the results. This paper carried out two sensitivity analysis of the results. The first one evaluates the contribution to the environmental impact of aluminum alloy sheet manufacturing. This alternate scenario considered the manufacture of aluminum alloy sheet made from recycled aluminum in replacement to primary aluminum. This scenario has been selected since the use of recycled aluminum is in practice feasible for the considered jurisdiction. A second sensitivity analysis by using Tool for the Reduction and Assessment of Chemical and other environmental Impacts (TRACI) method [44] was also carried out. This analysis will be helpful to verify the robustness of the obtained results from IMPACT2002+ method.

\section{Results and Discussion}

This study was carried out in order to determine the importance and contribution of LCA in the development process of WAL panels. The comparative LCA identify the environmental hotspots and burdens inside the laminated panels manufacturing process in Quebec, according to a cradle-to-gate approach.

\subsection{Analysis of Manufacturing Processes of Wood-Based Composite and of Aluminum Honeycomb Panels Without Lamination.}

LCA results (midpoint categories) for $1 \mathrm{~m}^{2}(1 \times 1 \times 0.10 \mathrm{~m})$ of wood-based composites and aluminum honeycomb are shown in Figure 3. In general, the total impact of wood-based composite manufacturing was 98 to $45 \%$ lower than the aluminum honeycomb manufacturing on several categories, except on aquatic and terrestrial ecotoxicity and on land occupation category; in both categories wood-based composites manufacturing generated highest negative impact. 


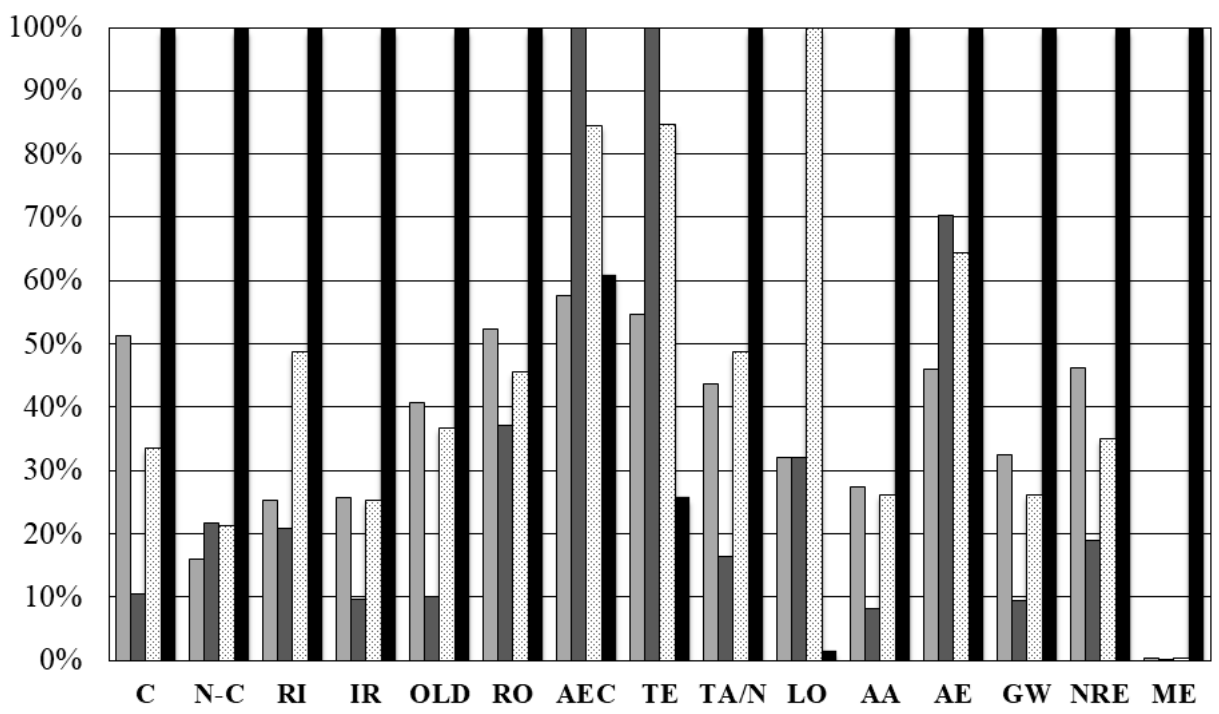

$\square \mathrm{MDF} \quad \square \mathrm{OSB} \quad \square$ Plywood $\quad$ Aluminum honeycomb

Figure 3. Characterization of the midpoint impacts of wood-based composites and aluminum honeycomb manufacturing processes.

The core manufacturing analysis of laminated panels at midpoint impact categories is presented below:

- Carcinogens category (C): Adhesive production (MUF, UF and PF resins) was the main contributor to negative impact, which represented $66-78 \%$ of total contributing emissions for wood-based composites. The $100 \%$ of contributions to this impact category was associated with epoxy resin for aluminum honeycomb.

- Non-carcinogens (N-C): Majority of emissions contributing to this impact category were associated with the treatment of wood ash mixture for MDF (52\%) and OSB (91\%), while heat production from hardwood chips was the main contributor for plywood $(84 \%)$. For aluminum honeycomb, treatment of red mud from bauxite digestion represented more than $88 \%$ of total contributing emissions.

- Respiratory inorganics (RI): MUF and UF resins (55\%), OSB production $(70 \%)$, and heat production from hardwood chips $(68 \%)$ were the main contributors to negative impact for MDF, OSB and plywood respectively. For aluminum honeycomb, 13\% and $12 \%$ of contributions to this impact category were associated with transport (transoceanic ship) of bauxite and aluminum production respectively.

- Ionizing radiation (IR): Electricity was the main contributor to IR, which represented $39 \%, 45 \%$ and $57 \%$ for MDF, OSB and aluminum honeycomb respectively, while melamine formaldehyde resin was the main contributor for plywood manufacturing (43\%).

- Ozone layer depletion (OLD): MUF and UF resins (72\%), pulpwood hardwood production (41\%) and MUF resin (75\%) were the main contributor for MDF, OSB and plywood respectively. Heat production from petroleum (39\%) was the main contributor for aluminum honeycomb manufacturing.

- Respiratory organics (RO): $55 \%, 41 \%$ and $41 \%$ of contributions to this impact category were associated with the MDF production, PF resin (OSB), and sawlog and veneer log production (plywood) respectively. $48 \%$ of contributions to this category were associated with aluminum primary liquid production for aluminum honeycomb.

- Aquatic ecotoxicity (AEC): Treatment of wood ash mixture was the main contributor to this category for MDF (72\%) and OSB (98\%), while heat production from hardwood chips for plywood 
(93\%). For aluminum honeycomb, treatment of red mud from bauxite digestion represented more than $49 \%$ of total contributing emissions.

- Terrestrial ecotoxicity (TE): Treatment of wood ash mixture was the main contributor to this category for MDF $(75 \%)$ and OSB $(98 \%)$, while heat production from hardwood chips was the main contributor for plywood (95\%). $43 \%$ of contributions to this category was associated with bauxite mine operation for aluminum honeycomb.

- Terrestrial acid/nutri (TA/N): $36 \%, 45 \%$ and $52 \%$ of contributions to this category were associated with MUF and UF resins (MDF), OSB production (OSB) and MUF resin (plywood) respectively. For aluminum honeycomb, $26 \%$ of contributions to this impact category were associated with transport of bauxite (transoceanic ship).

- Land occupation (LO): Wood production (softwood, hardwood and veneer log) was the most effective contributor to LO for MDF (99\%), OSB (100\%) and plywood (78\%).

- Aquatic acidification (AA): Adhesive production was the main contributor to AA, which represented $63 \%, 35 \%$ and $64 \%$ for MDF, OSB and plywood respectively. Aluminum production and transport of bauxite were the main contributor with $19 \%$ and $16 \%$ respectively, for aluminum honeycomb.

- Aquatic eutrophication (AE): Treatment of wood ash mixture was the main contributor to this category for MDF (47\%) and OSB (72\%), while heat production from hardwood chips was the main contributor for plywood $(73 \%)$. For aluminum honeycomb, Aluminum primary liquid production represented more than $52 \%$ of total contributing emissions.

- Global warming (GW): Once again, adhesive production was the main contributor to this category (64\%, 59\% and 76\% for MDF, OSB and plywood respectively). 30\% of contributions to this category was associated with aluminum production (aluminum primary liquid production).

- Non-renewable energy (NRE): Adhesive production was also the main contributor to this category (67\%, 65\% and $43 \%$ for MDF, OSB and plywood respectively). For aluminum honeycomb, hard coal (mine operation) for aluminum production $(14 \%)$ was the main contributor to this category.

- Mineral extraction (ME): Adhesive production was also the main contributor to this category $(87 \%$, $72 \%$ and $80 \%$ for MDF, OSB and plywood respectively). $98 \%$ of contributions to this category were associated with bauxite mine operation for aluminum honeycomb.

The adhesive production was the main hotspot in C, AA, GW, NRE, ME categories for wood-based composites manufacturing. This result is in accordance with previous studies in other regions, which also identified certain adhesive as the major contributor to the environmental impact $[11,20]$. The quantity and type of adhesive used in the manufacturing of wood-based composites are reflected in the results of impact categories, as shown by References [21,22]. For aluminum honeycomb manufacturing, the emissions associated with aluminum production was the main hotspot (Table 3), except in the $C$ and IR categories where epoxy resin and electricity (pressing) were the main hotspots respectively. These results are in accordance with the LCA study performed by Reference [34], which shows that primary aluminum production accounts for more than $50 \%$ of environmental impact.

The core manufacturing analysis was also performed at end-point level. Aluminum honeycomb manufacturing has a greater negative impact in human health, climate change and resources categories (Figure 4). While, plywood manufacturing showed greatest negative impact in the ecosystem quality category. This impact was generated mainly by the impact on the land occupation category associated with the land perturbation during the harvesting step. The plywood manufacturing used $0.021858 \mathrm{~m}^{3}$ of hardwood (saw log and veneer log), while MDF and OSB used $0.014717 \mathrm{~m}^{3}$ (softwood and wood chips) and $0.009579 \mathrm{~m}^{3}$ (hardwood) respectively. 
Table 3. Hotspots in wood-based composites and aluminum honeycomb manufacturing processes.

\begin{tabular}{|c|c|c|c|c|}
\hline \multirow{2}{*}{ Impact Category } & \multicolumn{4}{|c|}{ Hotspots } \\
\hline & MDF & OSB & Plywood & Aluminum Honeycomb \\
\hline Carcinogens & & Adhesive production (MUF, UF and PF resins) & & Epoxy resin \\
\hline Non-carcinogens & Treatment of wood ash mixture, pure, landfarming & Treatment of wood ash mixture, pure, landfarming & Heat production from hardwood chips & Treatment of red mud from bauxite digestion \\
\hline Respiratory inorganics & MUF and UF resins & OSB production & Heat production from hardwood chips & Transport (transoceanic) \\
\hline Ionizing radiation & Electricity & Electricity & MUF resin & Electricity (Pressing) \\
\hline Ozone layer depletion & MUF and UF resins & Pulpwood hardwood production & MUF resin & Petroleum and gas production (heat production) \\
\hline Respiratory organics & MDF production & PF resin & Sawlog and veneer log production & Coke (aluminum primary liquid production) \\
\hline Aquatic ecotoxicity & Treatment of wood ash mixture, pure, landfarming & Treatment of wood ash mixture, pure, landfarming & Heat production from hardwood chips & Treatment of red mud from bauxite digestion \\
\hline Terrestrial ecotoxicity & Treatment of wood ash mixture, pure, landfarming & Treatment of wood ash mixture, pure, landfarming & Heat production from hardwood chips & Bauxite mine operation \\
\hline Terrestrial acid/nutri & MUF and UF resins & OSB production & MUF resin & Transport (transoceanic) \\
\hline Land occupation & Pulpwood softwood production & Pulpwood hardwood production & Sawlog and veneer log production & Hard coal (mine operation) \\
\hline Aquatic acidification & & Adhesive production (MUF, UF and PF resins) & & Aluminum primary liquid production \\
\hline Aquatic eutrophication & Treatment of wood ash mixture, pure, landfarming & Treatment of wood ash mixture, pure, landfarming & Heat production from hardwood chips & aluminum primary liquid production \\
\hline Global warning & & Adhesive production (MUF, UF and PF resins) & & Aluminum primary liquid production \\
\hline Non-renewable energy & & Adhesive production (MUF, UF and PF resins) & & Hard coal (mine operation) \\
\hline Mineral extraction & & Adhesive production (MUF, UF and PF resins) & & Bauxite mine operation \\
\hline
\end{tabular}




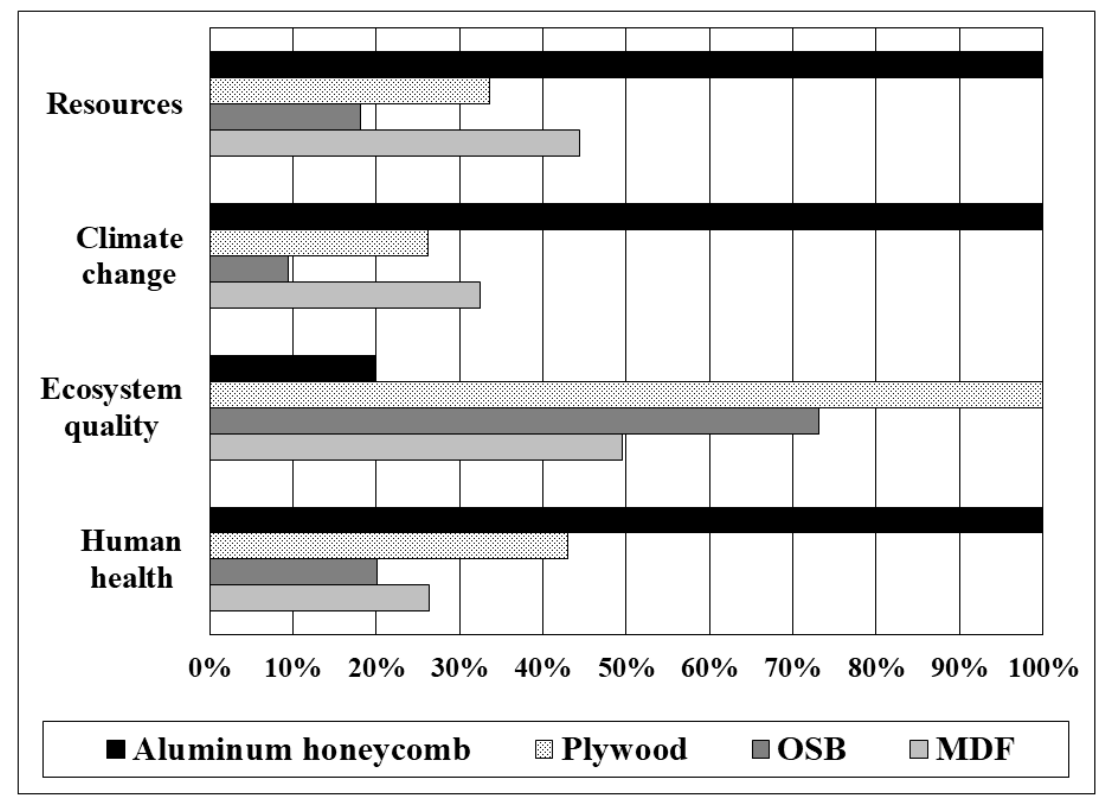

Figure 4. Comparison of wood-based composites manufacturing and aluminum honeycomb manufacturing by damage category.

The impact of MDF, OSB and plywood manufacturing represented $30 \%, 20 \%, 44 \%$ of negative impact respectively of aluminum honeycomb manufacturing in human health category; $36 \%, 10 \%$, $28 \%$ in climate change category; and $47 \%, 18 \%, 35 \%$ in resources category. The OSB showed a smaller negative impact in human health, climate change and resources categories, while aluminum honeycomb manufacturing showed a smaller negative impact in the ecosystem quality category.

\subsection{Analysis of Manufacturing Process of WAL Panels and AHP}

Table 4 shows the environmental impact of manufacturing process of WAL panels and AHP by damage categories (cradle-to-gate). The analyses showed that OSB aluminum-laminated panel manufacturing presented the best environmental performance in human health, climate change and resource categories. In contrast, the AHP manufacturing presented a greater negative impact in these three categories. The impacts in human health category of OSB, MDF and plywood aluminum-laminated panels manufacturing represented $69 \%, 71 \%$ and $77 \%$ respectively, compared to aluminum honeycomb panel manufacturing. In climate change category, the impact associated with OSB, MDF and plywood aluminum-laminated panels manufacturing represented $66 \%, 74 \%$ and $72 \%$ compared to aluminum honeycomb panel manufacturing, while in resources category represented $65 \%, 74 \%$ and $71 \%$. Finally, in ecosystem quality category, the impacts associated with aluminum honeycomb panel manufacturing represented $44 \%$ compared to plywood aluminum-laminated panel manufacturing. The impacts associated with OSB and MDF aluminum-laminated panel manufacturing represented $81 \%$ and $64 \%$ respectively.

Figure 5 shows the results of contribution analysis in each damage categories. The emissions associated with aluminum alloy sheets manufacturing were the main contributor to the environmental impact in human health, climate change and resources categories. However, the emissions associated with wood-based composite manufacturing was the highest contributor to ecosystem quality category. 
Table 4. IMPACT 2002+ end-point results: Comparison of WAL panels and AHP.

\begin{tabular}{ccccc}
\hline & \multicolumn{4}{c}{ LAMINATED PANELS } \\
\cline { 2 - 5 } Category & $\begin{array}{c}\text { MDF } \\
\text { Aluminum-Laminated } \\
\text { Panel }\end{array}$ & $\begin{array}{c}\text { OSB } \\
\text { Aluminum-Laminated } \\
\text { Panel }\end{array}$ & $\begin{array}{c}\text { Plywood } \\
\text { Aluminum-Laminated } \\
\text { Panel }\end{array}$ & $\begin{array}{c}\text { Aluminum } \\
\text { Honeycomb Panel }\end{array}$ \\
\hline $\begin{array}{c}\text { Human Health } \\
\text { (DALY) }\end{array}$ & $4.78 \times 10^{-5}$ & $4.62 \times 10^{-5}$ & $5.18 \times 10^{-5}$ & $6.65 \times 10^{-5}$ \\
$\begin{array}{c}\text { Ecosystem quality } \\
\left(\text { PDF }^{2 *} \text { yr) }\right.\end{array}$ & 10.40 & 13.10 & 16.20 & 7.13 \\
$\begin{array}{c}\text { Climate change } \\
\left(\text { kg CO } \text { CO }_{2} \text { eq }\right. \\
\text { Resources }\end{array}$ & 31.20 & 27.90 & 30.30 & 41.50 \\
$($ MJ primary) & $4.81 \times 10^{2}$ & $4.24 \times 10^{2}$ & $4.58 \times 10^{2}$ & $6.29 \times 10^{2}$ \\
\hline
\end{tabular}
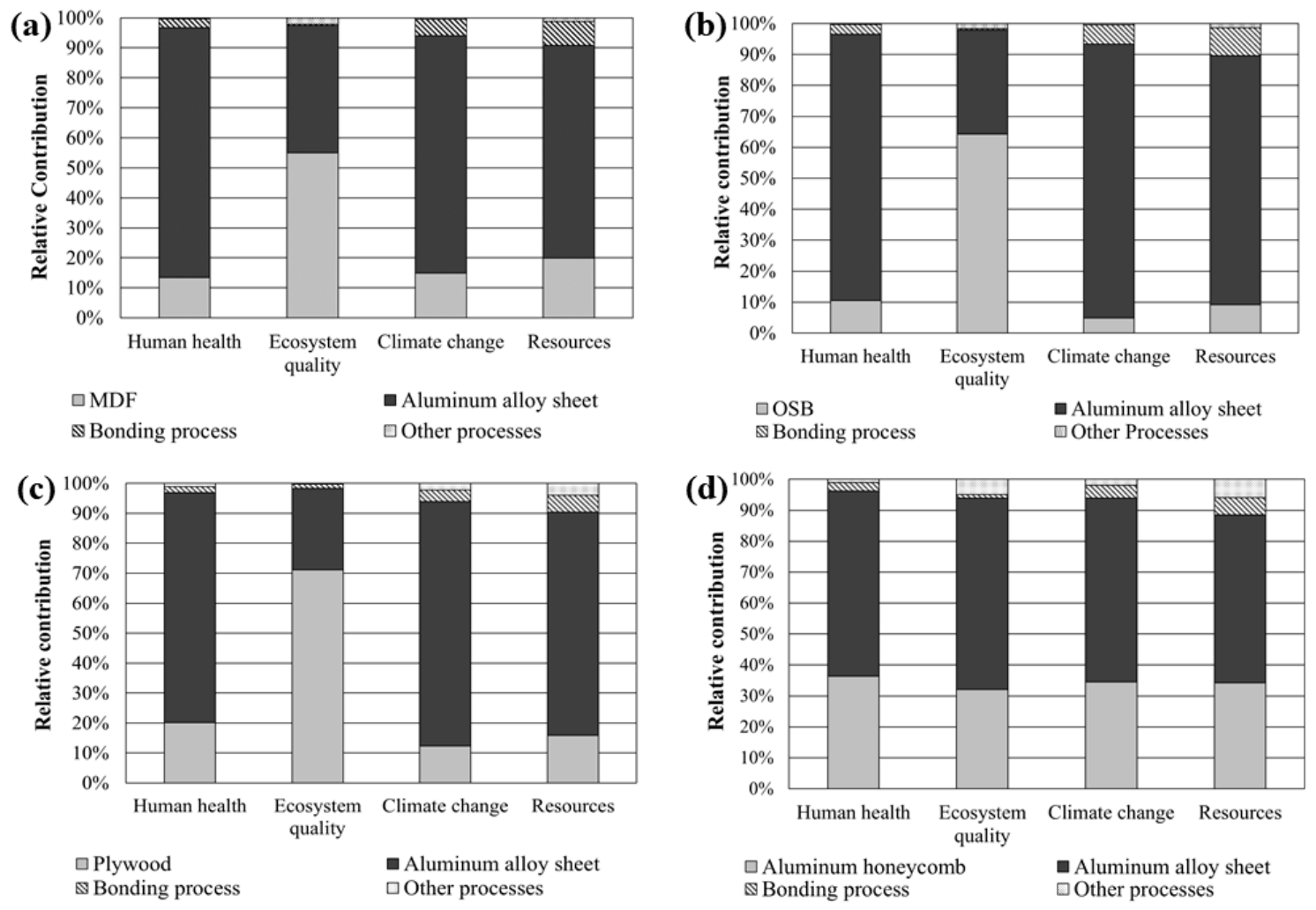

Figure 5. Relative contribution at end-point categories (in \%) of each manufacturing process of WAL panels and AHP. (a): MDF aluminum-laminated panel; (b): OSB aluminum-laminated panel; (c): Plywood aluminum-laminated panel; (d): Aluminum honeycomb panel.

On one hand, the contribution analysis of laminated panels in the climate change category showed that the greenhouse gas emissions as $\mathrm{CO}, \mathrm{CO}_{2}, \mathrm{CH}_{4}$ and $\mathrm{SF}_{6}$ from aluminum alloy sheets manufacturing represented more than $79 \%$ of the total negative impact for WAL panels. On the other hand, the greenhouse gas emissions by aluminum honeycomb manufacturing and aluminum alloy sheet manufacturing represented $94 \%$ of the negative impact total. $\mathrm{CO}_{2}$ involves the highest emissions contribution in WAL panels and AHP manufacturing (Table 5). The $\mathrm{CO}_{2}$ from aluminum alloy sheet manufacturing is mainly emitted by primary aluminum liquid production and heat production. The emissions of $\mathrm{CO}_{2}$ in wood-based composites manufacturing were mainly originating from adhesive production (2.85kg/MDF, $0.736 \mathrm{~kg} / \mathrm{OSB}$ and $2.801 \mathrm{~kg} / \mathrm{Plywood})$. 
Table 5. Emission of $\mathrm{CO}_{2}$ in $\mathrm{kg}$ (WAL panels and AHP). IMPACT 2002+ method.

\begin{tabular}{ccccc}
\hline & \multicolumn{4}{c}{$\mathrm{CO}_{2}$ Emissions in kg by Laminated Panels } \\
\cline { 2 - 5 } Materials/Processes & $\begin{array}{c}\text { MDF } \\
\text { Aluminum-Laminated } \\
\text { Panel }\end{array}$ & $\begin{array}{c}\text { OSB } \\
\text { Aluminum-Laminated } \\
\text { Panel }\end{array}$ & $\begin{array}{c}\text { Plywood } \\
\text { Aluminum-Laminated } \\
\text { Panel }\end{array}$ & $\begin{array}{c}\text { Aluminum } \\
\text { Honeycomb Panel }\end{array}$ \\
\hline Core manufacturing & 4.46 & 1.25 & 3.55 & 13.30 \\
Aluminum alloy sheet & 22.90 & 22.90 & 22.90 & 22.90 \\
manufacturing & 1.05 & 1.05 & 1.05 & 1.59 \\
Bonding process & 2.16 & 2.10 & 2.10 & 0.61 \\
Other processes & 30.60 & 27.30 & 29.60 & 38.40 \\
Total & & & & \\
\hline
\end{tabular}

The contribution analysis in the human health category showed that emissions associated with aluminum alloy sheet manufacturing represented $83 \%, 88 \%, 81 \%$ and $60 \%$ of total negative impact for the MDF aluminum-laminated panel, OSB aluminum-laminated panel, plywood aluminum-laminated panel and AHP, respectively, while the emissions associated with wood-based composites manufacturing represented $14 \%, 9 \%$, and $20 \%$ of total negative impact for three WAL panels. The contribution analysis in the resource's category showed that emissions associated with aluminum alloy sheet manufacturing was main contributor of total negative impact. Aluminum alloy sheets manufacturing represented $72 \%, 83 \%$ and $76 \%$ of total negative impact for MDF aluminum-laminated panel, OSB aluminum-laminated panel and plywood aluminum-laminated panel, respectively. While for AHP manufacturing represented $54 \%$ of total negative impact.

In ecosystem quality category, the emissions associated with wood-based composites were the main contributor of negative impact for WAL panels. The impact is specially generated in the treatment of wood ash mixture process and wood production process, while for AHP manufacturing, the emissions associated with aluminum production especially with bauxite mine operation and primary aluminum production were the main contributor.

The results have shown that the use of wood-based composites as core in laminated panels has an advantage compared to the aluminum honeycomb. However, the emissions associated with the consumption of resins as UF, MUF and PF in wood-based composites manufacturing are an important constraint at the environmental level. Therefore, the use of resin from renewable sources could improve the environmental profile of these composites and the WAL panels [22]. The results also show that emissions of aluminum alloy sheets manufacturing were the main contributor to environmental impact laminated panels. Consequently, replacing primary aluminum by recycled aluminum could also improve the environmental profile of laminated panels, mainly due to decrease in electricity consumption $[33,34]$. The results of analyses considering recycled aluminum are presented below.

The emissions associated with bonding process, which includes adhesive production (polyurethane or epoxy resin) and electricity process was the third contributor to the negative impact of laminated panels. The consumption of adhesive was higher in AHP $\left(0.200 \mathrm{~kg} / \mathrm{m}^{2}\right)$ in comparison with WAL panels $\left(0.130 \mathrm{~kg} / \mathrm{m}^{2}\right)$, resulting in a higher negative impact in all damage categories, except in ecosystem quality (Table 6).

The other production steps such as sanding, pressing, and degreasing do not contribute significantly to the total negative impact in all damage categories. In all cases, the contribution of all these other processes was less than $6 \%$ of total negative impact.

The environmental assessment of this study was limited to the laminated panels manufacturing as part of the product development. The prior studies demonstrated that WAL panels have potential to be used as structural panels, opening the door to a new range of applications [22]. The determination of another application can involve the variation of manufacturing parameters to meet with other requirements. To complete the study, the analysis of the use phase in a more defined context and end-of-life phase should be carried out, which could imply a variation in the impact results. 
Table 6. IMPACT 2002+ end-point results: Comparison of consummation of epoxy resin and polyurethane adhesive.

\begin{tabular}{ccccc}
\hline \multirow{2}{*}{ Category } & \multicolumn{3}{c}{ Adhesive Production } \\
\cline { 2 - 5 } & Epoxy Resin & Main Substances & Polyurethane Adhesive & Main Substances \\
\hline $\begin{array}{c}\text { Human Health } \\
\text { (DALY) }\end{array}$ & $9.21 \times 10^{-7}$ & $\mathrm{NOx}, \mathrm{SO}_{2}$ & $4.86 \times 10^{-7}$ & NOx, Particules $<2.5 \mathrm{um}$ \\
$\begin{array}{c}\text { Ecosystem quality } \\
\left(\mathrm{PDF}^{*} \mathrm{~m}^{2 *} \mathrm{yr}\right)\end{array}$ & 0.0435 & $\mathrm{NOx}, \mathrm{Zinc}$ & 0.0185 & $\mathrm{NOx}, \mathrm{Zinc}$ \\
$\begin{array}{c}\text { Climate change } \\
\text { (kg CO } \mathrm{CO}_{2} \text { eq) } \\
\text { Resources }\end{array}$ & 0.84 & $\mathrm{CO}_{2}, \mathrm{CH}_{4}$ & 0.573 & $\mathrm{CO}_{2}, \mathrm{CH}_{4}$ \\
(MJ primary) & 17.4 & Gas natural & 12.8 & Gas natural \\
\hline
\end{tabular}

\subsection{Sensitivity Analysis}

Alternative scenario: Use of recycled aluminum for the manufacture of aluminum alloy sheet. The aluminum alloy sheets manufacturing using recycled aluminum showed a dramatic decrease of the total negative impact. In the case of aluminum honeycomb panel manufacturing, the negative impact was nearly halved in all damage categories with the exception of ecosystem quality category. The reduction of total negative impact on this category was only $9 \%$. In the case of WAL panels manufacturing, the reduction of negative impact was also important in all damage categories except for ecosystem quality. The reduction of negative impact in the climate change category was between $74 \%$ and $65 \%$, in the human health category was between $77 \%$ and $67 \%$, while in the resources category the reduction was between $69 \%$ and $60 \%$ for WAL panels. The main contributor to the negative impacts on ecosystem quality category was the wood-based composite manufacturing process. Therefore, the reduction of negative impact in this category was only $17 \%, 21 \%$ and $9 \%$ for MDF aluminum-laminated panel, OSB aluminum-laminated panel and plywood aluminum-laminated panel, respectively.

Method comparison: Impact 2002+ method and TRACI method. The comparison between laminated panels was conducted with TRACI method, to test if this affects the results, and at the same time to verify the robustness of the results obtained from IMPACT2002+ method. Figure 6 shows the results of both methods.

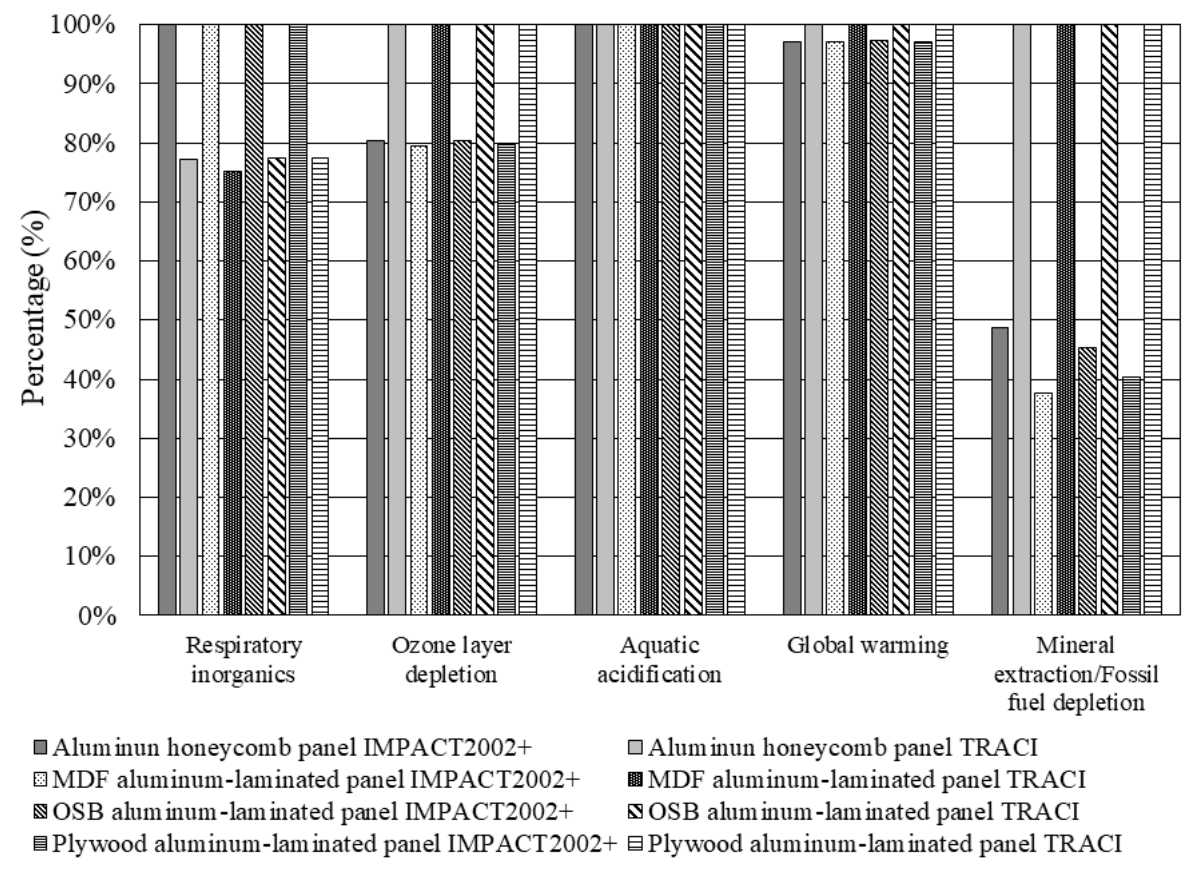

Figure 6. Sensitivity analysis results: impact category according to IMPACT 2002+ method compared to TRACI method. 
The analysis at mid-point categories demonstrated that the results showed similar trends in aquatic acidification and global warming categories. For respiratory inorganic category, LCA result using TRACI method was less than IMPACT2002+. In contrast, for ozone layer depletion and mineral extraction categories, the LCA result using the IMPACT2002+ method was less than the result obtained using the TRACI method.

\section{Conclusions}

A comparative LCA study of the manufacturing of three WAL panels with different types of cores and an AHP was performed. The functional unit was defined as laminated panel manufacturing of one square meter per $10 \mathrm{~mm}$ of thickness able to withstand a load of $6.0 \mathrm{kgf} / \mathrm{mm}^{2}$, as an interior floor. The LCA study identified the contribution of each material at environmental impacts throughout the laminated panels manufacturing. The main conclusions of LCA study in the product development process of laminated panels are as follows.

In terms of product, the comparison of WAL panels and AHP allowed identify that wood-based composites are the best choice as core in laminated panels manufacturing. Among panel components considered in this LCA study, OSB manufacturing had the lowest impact on the human health, climate change and resources categories of all the wood composites. On the other hand, MDF manufacturing had the lowest impact on ecosystem quality category. Furthermore, polyurethane adhesive is the best option compared to epoxy resin. Polyurethane adhesive had the lowest impact on all damage categories, except on ecosystem quality category. The production steps (sanding, pressing, and degreasing) do not contribute significantly to the total negative impact in all damage categories. Finally, the utilization of aluminum alloy sheets is the main contributor to negative impact in each laminated panel.

For the final product, the results indicate that WAL panels presented the lower negative impact than AHP on climate change, human health and resources categories, while AHP manufacturing presented lowest negative impact on ecosystem quality category. The environmental advantages of the WAL panels can be due to the reduction of primary aluminum quantity and/or the selection of wood-based composite compared to AHP. LCA results also show the environmental benefits of the selection of wood-based composites as core. However, analysis of use and end-of-life phases could modify the results. The emissions associated with aluminum primarily in aluminum honeycomb manufacturing contributed most to negative environmental impacts.

Contribution analysis results of WAL panels showed that emissions related to aluminum alloy sheets manufacturing were the main cause of the negative impact. These emissions contributed between $71 \%$ and $88 \%$ of the total negative impact on human health, climate change and resources categories. The emissions associated with wood-based composites were between $5 \%$ and $20 \%$ of the total negative impact on human health, climate change and resources categories. In contrast, for the ecosystem quality category were between $55 \%$ and $72 \%$. The negative impact of wood-based composites manufacturing was mainly due to adhesive production process emissions. Therefore, the selection of a resin from renewable sources in the manufacturing of wood-based composite could decrease the environmental burden. Likewise, the utilization of recycled aluminum as material for aluminum alloy sheets manufacturing resulted in a significant improvement in the environmental impacts of laminated panels, being an alternative in the development process of WAL panels.

The study demonstrated the usefulness of LCA methodology in the decision-making in the development process of WAL panels. WAL panels manufacturing is a better environmental option compared to AHP manufacturing. Therefore, WAL panels could replace AHP where material weight is not critical, considering that the first is heavier, but both have comparable mechanical properties. In conclusion, WAL panels should be considered as a serious alternative to AHP.

Author Contributions: Conceptualization, P.B.; methodology, B.A. and F.S.; writing-original draft preparation, F.S.; writing-review and editing, P.B., R.B., B.A. and C.B. All authors discussed the results and commented on the manuscript.

Funding: This research was funded by the Natural Sciences and Engineering Research Council of Canada. 
Acknowledgments: The authors would like to thank the Natural Sciences and Engineering Research Council of Canada-NSERC Project N RDC PJ386935 for their support during the whole project.

Conflicts of Interest: The authors declare no conflict of interest.

\section{References}

1. Nielsen, P.H.; Wenzel, H. Integration of environmental aspects in product development: A stepwise procedure based on qualitative life cycle assessment. J. Clean. Prod. 2002, 10, 247-257. [CrossRef]

2. Chang, D.; Lee, C.K.M.; Chen, C.-H. Review of life cycle assessment towards sustainable product development. J. Clean. Prod. 2014, 83, 48-60. [CrossRef]

3. La Rosa, A.; Cicala, G. LCA of fibre-reinforced composites. In Handbook of Life Cycle Assessment (LCA) of Textiles and Clothing; Woodhead Publishing Series in Textiles: Catania, Italy, 2015; Volume 172, 377p.

4. Bovea, M.D.; Vidal, R. Increasing product value by integrating environmental impacts, costs and customer valuation. J. Resour. Conserv. Recycl. 2004, 41, 133-145. [CrossRef]

5. González-García, S.; Feijoo, G.; Widsten, P.; Kandelbauer, A.; Zikulnig-Rusch, E.; Moreira, M. Environmental performance assessment of hardboard manufacture. Int. J. Life Assess. 2009, 14, 456-466. [CrossRef]

6. Puettmann, M.; Oneil, E.; Kline, E.; Johnson, L. Cradle to Gate Life Cycle Assessment of Oriented Strandboard Production from the Southeast; University of Washington: Seattle, WA, USA, 2013; 35p.

7. Rashid, A.F.; Yusoff, S. A review of life cycle assessment method for building industry. Renew. Sustain. Energy Rev. 2015, 45, 244-248. [CrossRef]

8. $\quad$ Puettmann, M.; Oneil, E.; Wilson, J. Cradle to Gate Life Cycle Assessment of U.S. Medium Density Fiberboard Production; University of Washington: Seattle, WA, USA, 2013; 26p.

9. Rivela, B.; Moreira, M.T.; Feijoo, G. Life cycle inventory of Medium Density Fibreboard. Int. J. LCA 2007, 12, 143-150. [CrossRef]

10. Wilson, J. Medium Density Fiberboard (MDF): A Life-cycle Inventory of Manufacturing Panels from Resource through Product; Corrim: Phase II. Final Report; Oregon State University: Corvallis, OR, USA, 2008; 50p. Available online: https:/corrim.org/wp-content/uploads/2018/03/lci-medium-density-fiberboard-panelsresource-through-product.pdf (accessed on 13 March 2017).

11. Zeller, V.; Richard, A.; Degrez, M.; Thyssen, N.; De Boever, L. Life Cycle Assessment of Medium Density Fibreboard LCA at Product Level; Project Report 3.4 v.2; ENECOBOIS: Brussels, Belgium, 2015; 38p.

12. Moro Piekarski, C.; de Francisco, A.C.; Mendes da Luz, L.; Kovaleski, J.L.; Lopes Silva, D.A. Life cycle assessment of medium-density fiberboard (MDF) manufacturing process in Brazil. Sci. Total Environ. 2017, 575, 103-111. [CrossRef]

13. Wang, S.; Wang, W.; Yang, H. Comparison of Product Carbon Footprint Protocols: Case Study on Medium-Density Fiberboard in China. Int. J. Environ. Res. Public Health 2017, 15, 2060. [CrossRef] [PubMed]

14. Kline, E. Gate-to-gate life-cycle inventory of oriented strandboard production. Wood Fiber Sci. 2005, 37, 74-84.

15. Ferro, F.S.; Silva, D.A.; Lahr, F.A.; Argenton, M.; González-García, S. Environmental aspects of oriented strand boards production. A Brazilian case study. J. Clean. Prod. 2018, 183, 710-719. [CrossRef]

16. Puettmann, M.; Oneil, E.; Wilson, J.; Johnson, L. Cradle to Gate Life Cycle Assessment of Softwood Plywood Production from from the Southeast; University of Washington: Seattle, WA, USA, 2013; 35p.

17. Puettmann, M.; Oneil, E.; Wilson, J.; Johnson, L. Cradle to Gate Life Cycle Assessment of Softwood Plywood Production from the Pacific Northwest; University of Washington: Seattle, WA, USA, 2013; 34p.

18. EPA. Framework for Assessing Biogenic $\mathrm{CO}_{2}$ Emissions from Stationary Sources: U.S. Environmental Protection Agency, Office of Air and Radiation Office of Atmospheric Programs, Climate Change Division. 2014. Available online: https://www.epa.gov/climatechange/november-2014-revisedframework-assessing-biogenic-co2-emissions-stationary-sources (accessed on 20 October 2017).

19. Beauregard, R.; Bernier, P.; Bouthillier, L.; Levasseur, A.; Paré, D.; St-Laurent-Samuel, A.; Thiffault, E. The Use of Biomass to Reduce Greenhouse Gaz Emissions in Quebec; Scientific advisory report; the Ministry of Natural Resources of Québec: Quebec City, QC, Canada, 2012; 19p. Available online: https://cfs.nrcan.gc.ca/ publications?id=34300 (accessed on 15 January 2017). 
20. Dos Santos, M.F.N.; Battistelle, R.A.G.; Bezerra, B.S.; Varum, H.S. Comparative study of the life cycle assessment of particleboards made of residues from sugarcane bagasse (Saccharum spp.) and pine wood shavings (Pinus elliottii). J. Clean. Prod. 2014, 64, 345-355. [CrossRef]

21. Wilson, J. Life-cycle inventory of formaldehyde-based resins used in wood composites in terms of resources, emissions, energy and carbon. Wood Fiber Sci. 2010, 42, 125-143.

22. Silva, D.A.L.; Rocco Lahr, F.A.; Varanda, L.D.; Christoforo, A.L.; Ometto, A.R. Environmental performance assessment of the melamine-urea-formaldehyde (MUF) resin manufacture: A case study in Brazil. J. Clean. Prod. 2015, 96, 299-307. [CrossRef]

23. Batouli, S.; Zhua, Y.; Narb, M.; D'Souza, N. Environmental performance of kenaf-fiber reinforced polyurethane: A life cycle assessment approach. J. Clean. Prod. 2014, 66, 164-173. [CrossRef]

24. La Rosa, A.; Reccab, G.; Summerscalesc, J.; Latteria, A.; Cozzoa, G.; Cicalaa, G. Bio-based versus traditional polymer composites. A life cycle assessment perspective. J. Clean. Prod. 2014, 74, 135-144. [CrossRef]

25. Song, Y.; Youn, J.; Gutowski, T. Life cycle energy analysis of fiber-reinforced composites. Compos. Part A 2009, 40, 1257-1265. [CrossRef]

26. Umair, S. Environmental Impacts of Fiber Composite Materials. Study on Life Cycle Assessment of Materials used for Ship Superstructure. Master's Thesis, Royal Institute of Technology, Stockholm, Sweden, 2006; 63p.

27. Xun, X.; Jayaramana, K.; Morin, C.; Pecqueux, N. Life cycle assessment of wood-fibre-reinforced polypropylene composites. J. Mater. Process. Technol. 2008, 198, 168-177.

28. Liu, G.; Muller, D. Addressing sustainability in the aluminum industry: A critical review of life cycle assessments. J. Clean. Prod. 2012, 35, 108-117. [CrossRef]

29. Hong, J.; Zhou, J.; Hong, J.; Xu, X. Environmental and economic life cycle assessment of aluminum-silicon alloys production: a case study in China. J. Clean. Prod. 2012, 24, 11-19. [CrossRef]

30. Norgate, T.E.; Jahanshahi, S.; Rankin, W.J. Assessing the environmental impact of metal production processes. J. Clean. Prod. 2007, 15, 838-848. [CrossRef]

31. Sevigné-Itoiz, E.; Gasol, C.M.; Rieradevall, J.; Gabarrell, X. Environmental consequences of recycling aluminum old scrap in a global market. Resour. Conserv. Recycl. 2014, 89, 94-103. [CrossRef]

32. Tan, R.B.H.; Khoo, H.H. An LCA study of a primary aluminum supply chain. J. Clean. Prod. 2005, 13, 607-618. [CrossRef]

33. Zhang, Y.; Sun, M.; Hong, J.; Han, X.; He, J.; Shi, W.; Li, X. Environmental footprint of aluminum production in China. J. Clean. Prod. 2016, 133, 1242-1251. [CrossRef]

34. Aluminum Association Inc. The Environmental Footprint of Semi-Finished Aluminum Products in North America; A Life Cycle Assessment Report; Aluminum Association. Inc.: Arlington County, VA, USA, 2013; 123p.

35. Segovia, F.; Blanchet, P.; Barbuta, C.; Beauregard, R. Aluminum-laminated panels: Physical and mechanical properties. BioResources 2015, 10, 4751-4767. [CrossRef]

36. International Organization for Standardization (ISO). Environmental Management-Life Cycle Assessment_-Principles and Framework; International Organization for Standardization: Geneva, Switzerland, 2006; Standard 14040.

37. International Organization for Standardization (ISO). Environmental Management-Life Cycle Assessment-Requirements and Guidelines; International Organization for Standardization: Geneva, Switzerland, 2006; Standard 14044.

38. Ecoinvent Centre. Ecoinvent Database. Swiss Centre for Life Cycle Inventories. 2018. Available online: https://www.ecoinvent.org/database/ecoinvent-35/ecoinvent-35.html (accessed on 15 March 2019).

39. American Society for Testing and Materials. Standard Test Methods for Evaluating Properties of Wood-Based Fiber and Particle Panel Materials; ASTM D1037; ASTM International: West Conhohocken, PA, USA, 2012.

40. Stark, N.; Cai, Z.; Carll, C. Woo-based Composite Materials. Panel products, Glued-Laminated Timber, Structural Composite Lumber, and Wood-Nonwood Composite Materials. In Wood Handbook Wood as an Engineering Material; General Technical Report FPL-GTR-190; U.S. Department of Agriculture, Forest Service, Forest Products Laboratory: Madison, WI, USA, 2010; 508p.

41. Beaulieu, D. Les Caractéristiques de L'aluminium Structural, 2nd ed.; Les Presses de l'aluminium: Saguenay, QC, Canada, 2013; 132p.

42. Bitzer, T. Honeycomb Technology: Materials, Desing, Manufacturing, Applications and Testing; Chapman \& Hall: London, UK, 1997; 233p. 
43. Jolliet, O.; Saadé, M.; Crettaz, P. Analyse du Cycle de Vie: Comprendre et Realiser un Écobilan; Presses Polytechniques et Universitaires Romandes.Lausanne: Lausanne, Suisse, 2010; 242p.

44. Bare, J.C. TRACI 2.0-The Tool for the Reduction and Assessment of Chemical and other environmental Impacts. In Clean Technologies and Environmental Policy; Springer: New York, NY, USA, 2011; Volume 13, pp. 687-696.

(C) 2019 by the authors. Licensee MDPI, Basel, Switzerland. This article is an open access article distributed under the terms and conditions of the Creative Commons Attribution (CC BY) license (http://creativecommons.org/licenses/by/4.0/). 